\title{
OCTAVIO PAZ E A BUSCA DA PRESENÇA ${ }^{9}$
}

\section{VINÍCIUS DE OLIVEIRA PRADO}

RESUMO: Este texto visa a explorar a significação da noção de presente, presença e instante para Octavio Paz (1914-1998), poeta mexicano e ensaísta crítico. Em suas Obras Completas (1991), Paz nomeou o primeiro volume La casa da la presencia. Iniciamos este ensaio com uma exegese do título que, a nosso ver, é uma das muitas metáforas que o mexicano atribuiu à poesia e também uma importante chave de compreensão do seu pensamento. A poesia, manancial de sentidos e significados, seria, portanto, o local por excelência da experiência do presente: marcado por um alargamento sensorial e pela nietzschiana "eterna vivacidade". Para Paz, o ser humano é tempo, em sua forma de ser e existir. Por estas razões, Paz pode ser considerado um autor que, na sua interpretação do contemporâneo, propõe uma visão de tempo que se coaduna à sua poética, a qual classificamos como uma poética do instante, uma vez que faz do instante poético o núcleo da experiência sensível, isto é, experiência estética da vivacidade e da transmutação do próprio tempo, bem como da história. Compreender o tempo em Paz implica em responder, também, à questão: seria o instante temporal evocado pela poesia um recorte sincrônico - entendido como justaposição - ou o poeta, em sua pretensão de totalidade, busca tornar a palavra uma unidade do absoluto? A nosso ver, a experiência da presença guarda uma resposta para esse par tensionado, que exploramos neste ensaio, além de outras questões que constituem a experiência da presença, objetivo último do poeta.

PALAVRAS-ChAVE: Presença; instante; presente; poesia; história; Octavio Paz.

9 Este ensaio foi originalmente apresentado no evento Jornada do Programa de Pós-graduação em Língua e Literaturas Espanhola e Hispano-americana do Departamento de Letras Modernas em novembro de 2019 sob o título: A imagem de tempo em Octavio Paz: justaposição ou unidade do absoluto? Este ensaio é resultado de pequenas alterações no texto original que conferiram a forma aqui apresentada. 
O primeiro volume das Obras Completas de Octavio Paz, selecionadas, editadas e organizadas pelo próprio poeta, levam o nome La casa de la presencia $(1991)^{10}$. Este é o primeiro de uma vasta bibliografia, organizada em doze tomos, cujo último volume se dedica à poesia completa do autor. Todo trabalho de leitura começa pelo título de uma obra: a que se deve este nome? Ora, a função de uma casa é, justamente, a morada, o habitar. É no interior dela que, sozinhos ou em companhia, encontramos o real significado da intimidade, seja do outro para conosco ou seja da interioridade de cada um consigo mesmo. A casa, enquanto sustentáculo vital, substrato e suporte, oferece uma condição de existência e de ser. Trata-se do suporte à vida nua e ao seu desenrolar. Em países do chamado "terceiro mundo", a casa possui conotação política: é um direito a ser conquistado, assim como o é a terra. Octavio Paz, enquanto latino-americano consciente de sua condição, reconhece, em O Labirinto da Solidão (1950) que os mexicanos tiveram originalidade política quando, na revolução de 1910, conclamaram o direito à terra através da Reforma Agrária, em decorrência da violação histórica que os calpulli, espécie de propriedade comunal, sofreram no processo da Conquista (PAZ, 2014). A casa, portanto, não é um bem estático, garantido, tampouco onipresente, mas algo que se constrói, que se conquista, através de elaboração e trabalho. Mas, de qual tipo de casa fala Octavio Paz neste volume? E o que seria a presença, qualificador da casa? Em seu discurso, a propósito do recebimento do prêmio Nobel em 1990, Paz alude ao presente como a dimensão temporal em que vigora a presença (PAZ, 2017). O caminho que percorre para considerar o presente, este ponto intermediário, encarado como a passagem fugaz entre a tríade que compõe com passado e futuro - como o tempo por excelência da realização da presença - merece uma breve explicação, para fazermos um recorte do campo de experiências cuja intensidade nos desloca e espanta. A princípio, podemos adiantar Octavio Paz pensa as experiências do amor, da revolta e da festa como irrupções da temporalidade presente do "agora”.

10 Ano referente à primeira edição. 
A revolta, como nos mostraram os anos de 1968 na França, no México e no restante do mundo e como, quiçá, nos mostra agora o Chile11, é um evento conduzido pela fortuna, pelo imponderável, pela linha tênue esticada na tensão entre determinação e liberdade. A revolta não é um projeto, ela talvez se conecte com o passado, fazendo reviver alguns mortos, mas sempre em detrimento de um aqui e agora determinados e motivados em torná-los Lázaro, isto é, ressurretos do esquecimento e das inúmeras camadas históricas que os obnubilaram ao longo do tempo. Apesar da acepção caótica, para Paz, a palavra revolta converte-se em reforma, em decorrência de uma aliança combinatória entre protestantismo e positivismo. Contudo, revoltar-se é voltar uma segunda vez, revisitar um tempo em que o caos era prévio à ordem. Em Corriente Alterna (1973), Octavio Paz estabelece uma distinção entre os termos políticos deste campo, a transformação política, em um texto cujo título é, justamente, Revolta, Revolução, Rebelião. Nele, o poeta diz que, apesar de estar imbuída pelos signos contemporâneos de apreço à ordem, respeito à autoridade, graças à sua proximidade com o surgimento do termo "reforma", revolta "é uma palavra plebeia" (PAZ, 2009, p. 262). Ademais, Paz reconhece que a revolta possui uma relação íntima com o presente, pois se trata de uma manifestação que converte o agora em um "presente caótico ou tumultuoso". Nesta obra, Paz conclui que os significados de revolta e revolução estão bem condensados na palavra rebelião, pois como "a primeira, [rebelião] é protesto espontâneo frente ao poder; como a segunda, encarna o tempo cíclico que põe acima o que estava abaixo, em um girar sem fim. O rebelde, anjo caído ou titã, é o eterno inconformado" (Idem, p.265). A manifestação da revolta seria, portanto, uma eclosão do tempo plural: aquele que converge no mesmo instante a potência ancestral do mito - ainda que sem mito - e a espontaneidade do presente, advindo de um lastro que é, como dissemos acima, marcado por um determinado passado ou uma certa tradição.

A festa, por sua vez, é um manancial que, ainda que intente fazer vicejar a continuidade cósmica do tempo em sua tríade, também deve celebrar o agora para manter o amanhã. O brinde, os fogos, as barracas, as brigas, os bêbados, o

11 A escrita deste texto se deu durante a eclosão de manifestações e protestos no Chile, iniciados em outubro de 2019, contra as desigualdades herdadas do modelo econômico instaurado pelo ditador Augusto Pinochet (1973-1990). 
hedonismo que se volve abstinência, a abundancia que se converte em austeridade, a devassidão que se transforma em puritanismo, em suma - para usarmos os termos presentes em Conjunções em Disjunções (1979) -, o signo corpo que oscila ao não-corpo, movimentando um polo dialético que arrebenta as contradições no dia em que se festejam a vida e a morte. Paz vê na festa um acontecimento ritual, onde sagrado e profano se dão as mãos em uma reconstituição espacial do tempo originário. Em O Labirinto da Solidão, o mexicano diz que a festa dos mortos no México é um dos melhores exemplos da conciliação dos contrários neste tempo idílico e "outro”. Nas palavras do autor, "tudo se dá num mundo encantado, o tempo é outro tempo (situado num passado mítico ou numa pura atualidade); o espaço em que se transcorre muda de aspecto, se desliga do resto da terra, se enfeita e se transforma num "lugar de festa"”(PAZ, 2014, 52) Transmutação do tempo que implica em uma transmutação do lugar. A festa também desafia a ordem, ao brincar com ela e estabelecer a seriedade das hierarquias num universo lúdico em que os papéis sociais trocam e se contradizem. Ainda que não seja uma sublevação da ordem, no sentido revolucionário do termo, para Paz, é correto dizer que a festa é uma revolta, no sentido literal da palavra, "pois na confusão que ela provoca, a sociedade se dissolve, se afoga enquanto organismo governado por certas regras e certos princípios. Mas se afoga em si mesma, no seu caos ou liberdade original (Idem, p. 53) A festa está atrelada ao tempo cíclico, não obstante prende-se ao calendário. Além disso, se a entendermos como função social, numa matriz funcionalista, a festa corroboraria no reforço da coesão social. Graças a ela,

o grupo sai purificado e fortalecido desse banho de caos. Mergulhou em si, nas próprias entranhas de onde saiu. Em outras palavras, a Festa nega a sociedade como conjunto orgânico de formas e princípios diferenciados, mas a afirma como fonte de energia e criação. É uma verdadeira recriação, ao contrário das festas modernas, que não exigem nenhum rito ou cerimônia, individuais e estéreis como o mundo que as inventou (PAZ, 2014, p.52)

Instante de comunhão, a festa antecede o retorno à vida profana do trabalho, do lucro e da solidão. Contudo, sabemos que assim como os ponteiros do 
relógio se movem em círculos, ela retornará no próximo feriado, no próximo carnaval, no próximo encontro com o outro. Nenhum dos termos é absoluto e a alternância entre repressão e licença se mantém num par binário constante.

Por fim, dentre os instantes da presença, a experiência amorosa, como retratada em La llama doble: amor y erotismo (1993) também é um evento cuja lógica nos escapa, tendo em vista que o misto de "acaso" e "objetividade", como Octavio Paz bem incorporou a partir dos escritos surrealistas, se funde no interior de um instante capaz de transcender a memória e o próprio tempo. Este instante, alargando sensorialmente a nossa percepção do próprio presente e transmutando-o em eternidade ou, para retomar o termo que Nietzsche emprega, e Paz bem observa em A Busca do Presente, "eterna vivacidade"12, é a substância que preenche o presente. A definição que Paz constrói do amor, ao mapear o sentimento, distinguindo-o da ideia, é a seguinte: “Amor en la forma sumaria en que lo he definido [...]: misteriosa inclinación pasional hacia una sola persona, es decir, transformación del "objeto erótico" en un sujeto libre y único" (PAZ, 1993, p.36). O presente se faz perceber através destas experiências, ele é o tempo da presença e nossa percepção acerca dele se dará pela vivacidade. $\mathrm{O}$ amor, sendo uma delas, expande a sua realização no além-tempo. Em La llama doble, Paz recupera a máxima de Quevedo: “polvo serán, mas polvo enamorado”. A ideia romântica de que o amor subsiste à morte, à doença e às efemeridades do mundo o consagra como a mais vívida das experiências, capaz de subsistir ao próprio fim da vida. Por isso, Octavio Paz concluirá que o instante amoroso se assimila ao instante trágico. Ainda em La llama doble, o mexicano diz:

el amor humano es la unión de dos seres sujetos al tiempo y a sus accidentes: el cambio, las pasiones, la enfermedad, la muerte. Aunque no nos salva del tiempo, lo entreabre para que, en un relámpago, aparezca su naturaleza contradictoria, esa vivacidad que sin cesar se anula y renace y que, siempre y al mismo tiempo, es ahora y es nunca. Por esto, todo amor, incluso el más feliz, es trágico.(PAZ, 1993, p.112)

\footnotetext{
12 "Já dizia Nietzsche: "Não à vida eterna, mas a eterna vivacidade: eis o que importa"” (PAZ, 2017, p. 25).
} 
O amor, “azar objetivo” cuja definição bretoniana é a de uma forma de necessidade exterior que abre caminho no inconsciente humano, cruza-se à ideia de acidente necessário. Vaso comunicante, esta ideia de matriz surrealista joga com dois polos contrários que se encontram sem anular-se. Para Paz, esta fusão só pode ser possível dentro da temporalidade presente, graças ao seu caráter incessante e movente.

Por esta razão, as experiências citadas anteriormente, as quais poderiam ser agregadas à experiência religiosa, mística e mágica, são aquelas em que o instante se alarga e nos retira do interior da cronologia cotidiana. Contudo, ainda não está claro, o que é a presença? Por que ela figura como o elemento comum entre todas estas experiências que são, a princípio, tão díspares? Ademais, o que diferencia presente e presença? Qual sua relação?

A presença não é a mera constatação da existência, não é uma medição do peso que este fato bruto implica. Poderíamos defini-la como um instante de lucidez, em que as coisas se aclaram e se avivam por si mesmas. Esta lucidez é o encontro momentâneo do ser humano com o sentido do ser e da existência. Este instante, ainda que aquebrantado pela consciência crítica em seus arroubos de ironia, é a porta de entrada da presença e das qualidades que tornarão a experiência do presente mais intensa e vivificadora. Em O Arco e a Lira (1956), o primeiro livro a compor suas Obras Completas, Octavio Paz afirma, remetendo-se a Breton, que "la véritable éxistence est ailleurs" para, com isto, indicar o seu oposto, no caso, o fato de que a verdadeira existência é aqui e é agora. Porém, o desafio desta experiência que se passa no agora é a nossa dificuldade em nomeála, em dizê-la, em verbalizá-la. Em seus percursos pela tradição hindu e budista, sobretudo em suas vertentes tântricas, Paz verificará que a afirmação do corpo leva, muitas vezes, ao silêncio do espírito. A sabedoria perfeita (Prajñāpāramitā) do budismo Mahayana implica, muitas vezes, no silêncio. A contemplação do Nirvana é uma não-contemplação, é uma experiência nadificadora, da qual nada se diz e da qual nada se pode dizer. Neste meio, a presença pode figurar como o contrário do Nada, uma vez que conecta a tudo e impregna a todas as coisas de sentido. Contudo, o desafio da linguagem se põe da mesma forma. Como dizê-la? Existe algum espaço onde o dizer desta presença se torne convidativo? Ora, para Octavio Paz, este espaço existe e é justamente onde a presença pode ser sentida em sua intimidade profunda, seja na experiência em que estiver ocorrendo. 
Trata-se da "casa da presença", figura dada pelo autor à poesia. A poesia responde a um apelo primário e a uma necessidade imperiosa de dizer e isso, por sua vez, implica na demanda de nomear o inominável e de buscar dizer o indizível. Chamar esta arte de compor versos de forma rítmica e analógica já é, por sua vez, exercer a operação mais poética da linguagem: criar uma metáfora.

Este primeiro volume de suas obras completas reúne três obras, em suas edições finais, além de El Arco y la Lira (1956), temos Los hijos del limo (1974) e La otra voz (1990). Nestas três obras-questões, Octavio Paz reflete sobre a poesia de um ponto de vista crítico e poético. Não raro, o papel do ensaísta se confunde com o do poeta e temos a impressão de estarmos lendo versos no momento em que o autor busca forçar ao limite os poderes analíticos da razão crítica. Outrora, em ensaios que remetiam à antropologia cultural, Octavio Paz reconheceu que, apesar de ocupar um papel de teórico, em momento nenhum de sua vida deixou de ser um poeta. Neste sentido, convém dizer que tanto em sua obra poética como em sua obra ensaística, Octavio Paz reconhece que pensa e poetiza sempre em vistas do tempo.

Crítico da imagem de tempo da tradição linear, progressiva e sucessiva, em ritmo de marcha, que se instaurou na modernidade como consequência dos desdobramentos sociais, econômicos, filosóficos e políticos que possibilitaram a crítica ao arquetípico temporal das sociedades cristãs e medievais - a eternidade -, Paz procura pensar qual seria a imagem de tempo que vigora no agora. Mais do que buscar compreender a imagem do tempo que nos rege - e é preciso ressaltar esta relação de regência. Para Paz não existe, no plano da nossa existência cultural, senão uma relação onde o tempo figura como centro de nossa existência. Em O Arco e a Lira, sob forte influência heideggeriana, em seu capítulo dedicado à natureza do poema, mais especificamente ao seu ritmo, o poeta diz que "todo ritmo é sentido de algo". Esta noção de sentido carrega uma ambivalência: em primeiro lugar, como direção; em segundo, como significado, motivo. Ademais, ele acrescenta:

O ritmo não é medida, é tempo original. A medida não é tempo, é maneira de cal-
culá-lo. Heidegger nos mostrou que toda medida é uma "forma de tornar presente
o tempo". Calendários e relógios são maneiras de cadenciar nossos passos. Essa
apresentação implica redução ou abstração do tempo original: o relógio apresenta 
o tempo, e para apresentá-lo divide-o em porções iguais e carentes de sentido. A temporalidade - que é o próprio homem e que, portanto, dá sentido ao que toca é anterior à apresentação e ao que a torna possível. (PAZ, 2012, p.64)

O ser humano é tempo, em sua forma de ser e existir. Por estas razões, Paz pode ser considerado um autor que, na sua interpretação do contemporâneo, propõe uma visão de tempo que se coaduna à sua poética, a qual classificamos como uma poética do instante, uma vez que faz do instante poético o núcleo da experiência sensível, isto é, experiência estética da vivacidade e da transmutação do próprio tempo, bem como da história.

Ora, uma vez que a imagem de tempo teleológica e infinita da ideologia do progresso colapsou diante da iminência dos cataclismas climáticos e se mostrou frágil, enquanto crença e princípio-motor depositário de sentido, defronte às capacidades bélicas explicitamente exibidas ao longo da Guerra Fria, como o autor bem aponta em Tiempo Nublado (1983), Paz se questiona: como podemos vislumbrar uma imagem de tempo que venha significar e produzir sentido no mundo em que vivemos? Seria, então, diante deste vazio - o vazio que se revelou no arquétipo moderno (o futuro progressivo ou, em outra vertente ideológica, o futuro utópico) - que Octavio Paz irá propor um resgate do tempo próprio da poesia, o qual denomina, justamente, presente: tempo em que vigora a presença. Contudo, se esta imagem de tempo que é aquela que opera como resistência aos tempos que colonizam nosso presente, como ela se configura diante da história? É ela uma justaposição sincrônica ou opera como uma "unidade de absoluto", para além da própria história? Se a resposta para esta pergunta for a possibilidade da existência de ambos os sentidos no interior da experiência temporal paziana, como conciliar estes princípios que à primeira vista, parecem contraditórios e excludentes?

Neste caso, dois conceitos podem nos auxiliar na compreensão do paradoxo que parece estar presente no interior da visão que Octavio Paz tem acerca do tempo. Trata-se de dois princípios que aparecem em Los hijos del limo: os conceitos de ironia e analogia:

La analogía concibe al mundo como ritmo: todo se corresponde porque todo ritma y rima. La analogía no sólo es una sintaxis cósmica: también es una prosodia. Si el universo es un texto o tejido de signos, la rotación de esos signos está regido por el 
ritmo. El mundo es un poema; a su vez, el poema es un mundo de ritmos y símbolos. Correspondencia y analogía no son sino nombres del ritmo universal. (PAZ, 2003, p.389)

A analogia é o princípio do próprio fazer poético, é ela quem estabelece as pontes que fundam as metáforas. É graças a ela que o movimento poético básico, indicado por Paz em O Arco e a Lira, "isto é aquilo", se realiza e que cada coisa encontra o seu nome e seu correspondente. Para Paz, a analogia é pertencente a um tempo imemorial, mítico, desprovido de consciência histórica e finitude. Desprovido de rupturas e contradições. Sem consciência da finitude.

Por isso, o oposto da analogia é a ironia. Esta é resultado do tempo cronológico, linear, progressivo e histórico. Baudelaire a associa à figura da caveira: a ironia é a mortalidade e sua consciência de si. Se a analogia é um esquecer-se na coletividade, no canto poético que consagra o instante e funda a comunidade, a ironia é o poeta endividado cantando a perda da auréola aos convivas da taberna pouco convidativa aos espíritos aristocratas, mas aberta ao submundo dos plebeus. Sobre a ironia, Octavio Paz diz que ela é a quebra da unidade e da pretensão de sentido analógico e universal da palavra:

El mundo no es un conjunto de cosas, sino de signos: lo que llamamos cosas son palabras. Una montaña es una palabra, un río es otra, un paisaje es una frase. Y todas esas frases están en perpetua metamorfosis. El texto que es el mundo no es un texto único: cada página es la traducción y la metamorfosis de otra y así sucesivamente. El mundo es la metáfora de una metáfora. El mundo pierde su realidad y se convierte en una figura de lenguaje. En el centro de la analogía hay un hueco: la pluralidad de textos implica que no hay un texto original. (PAZ, 2003, p.389)

Estes dois princípios atuam no interior da poesia moderna, porém, são inconciliáveis. É graças a eles que assistimos ao jogo contraditório de profanação do sagrado e à sacralização do profano. Ao mesmo tempo em que a razão crítica pretende desconstruir um mundo para, a partir de seus mecanismos e instrumentos inquisitoriais, edificar uma nova realidade, seu caráter passional lhe impede de consagrar um mundo novo ou uma nova transcendência. Neste sentido, a paixão crítica, ethos da modernidade, é também a pedra de Sísifo que sempre retorna 
ao seu lugar, pois seu impulso de chegar ao topo sempre encontra a próxima crítica a empurrar a pedra - e todo o esforço de trazê-la ao cume - ladeira abaixo.

Contudo, o que nos indicam a analogia e a ironia em relação ao tempo? Ora, em primeiro lugar, a imagem de tempo que rege a analogia, sendo cíclica, rítmica, ritual e fundadora da linguagem, opera como aquela capaz de tornar a linguagem poética na experiência em que a presença, objeto último dos poemas de Paz, se fará presente. Será ela a desocultar esta realidade substancial e devolver o sentido às coisas: desnudar a transparência. Porém, como a citação anterior nos suscita, este sentido sempre é mutável, transitório e histórico, pois a história não é senão o local por excelência das mudanças e transformações. A questão seria, então, como conciliar a consciência da transitoriedade e a propensão ao estabelecimento de um princípio imutável e ordenador da realidade através da palavra poética? Como conciliar o profundo desejo de tocar o absoluto com a constatação de que a realidade, como o rio heraclitiano, é condenada a ser eterno devir? Para esta questão, Paz diz que não há solução dialética possível. Intercambiamos os princípios da ironia e da analogia involuntariamente, como se déssemos ouvidos a Parmênides de Eléia e a Heráclito de Éfeso simultaneamente. Ao mesmo tempo que nossa propensão à eternidade nos leva a desejar um princípio a-histórico, a história nos quebra e diz que o dia de hoje se conecta a uma escolha determinada de signos e metáforas que são, por sua vez, o desdobramento de signos e metáforas outrora escolhidos por uma tradição que encontrou, quiçá, já a sua ruptura. O rio da linguagem é o rio de Heráclito: não se volve a ele mais de uma vez e tudo o que nele adentra muda. Contudo, a pretensão do poeta é fundar a palavra do Ser: eterna e perfeita.

Em razão da consciência desta relação paradoxal, selecionamos um dos últimos poemas de Octavio Paz para pensarmos como o poeta constrói, no interior de sua própria poesia, uma resposta à necessidade imperiosa de falar e fazer vicejar a presença, mesmo diante de um oxímoro que poderia resultar em uma imobilidade do poeta. Trata-se do poema Nocturno de San Ildefonso, publicado originalmente na revista Plural (1974), em tradução do professor e poeta Horácio Costa, no qual destacamos os versos:

\section{A página}

tornou-se um formigueiro. 
O vazio

Estabeleceu-se na boca do meu estômago.

Caio

interminavelmente sobre esse vazio.

Caio sem cair.

Tenho as mãos frias,

os pés frios

-mas os alfabetos ardem, ardem.

O espaço

faz-se e se desfaz. (PAZ, 2015, p. 172)

Nestes versos, podemos vislumbrar como o princípio da ironia cai sobre o autor como a consciência de uma nulidade. $O$ vazio que se estabelece na boca do estomago é sintoma de um arroubo da consciência noturna: assim como a morte faz a sua visita a Ebenezer Scrooge em A christmas carol (1843) de Charles Dickens, representada sob o manto do fantasma do futuro, a figura da Noite apalpa a testa do poeta, invade seus pensamentos e lhe tira o sono. A onipresença da noite, junto aos signos verbo-visuais da cidade que o poeta vê crescer pela sua janela, em letreiros de neón, em chaminés fumegantes de fábricas, em sons e ruídos de máquinas que atravessam as horas, são contrastados pelas imagens naturais dos topos de árvores, da Lua e das parcas estrelas visíveis. Tais marcas modernas, tornadas tradicionais pela poética que desde Baudelaire retrata o artista sem auréola, deslocado em meio à modernização, coabitam um universo de símbolos que clamam por ressignificação, mas que disputam, por outro lado, um espaço cada vez mais escasso. A ardência do alfabeto nos remete ao fogo, elemento da transformação, cujo toque, se não destrói, muda radicalmente uma coisa em outra. Porém, o mesmo fogo que destrói, também é capaz de fundir.

No caso de Octavio Paz, a ironia lhe aparece como a consciência de sua mortalidade e de sua própria historicidade. Não obstante, neste mesmo poema, o poeta revisita o Colégio de San Ildefonso, espaço privilegiado de sua juventude, onde vivera os primeiros arroubos do amor e das paixões políticas. Porém, ainda que as imagens apareçam tingidas de intensidade nestas páginas, a consciência do distanciamento histórico não se apaga e o papel do autor se faz presente em cada verso: 
O jovem que caminha por este poema,

entre San Ildefonso e o Zócalo,

é o homem que o escreve:

esta página

também é uma caminhada noturna. (PAZ, 2015, p. 176)

O texto como caminhada remete a outros escritos, como El mono gramatico (1974) - publicado no mesmo ano de Nocturno de San Ildefonso - onde o poeta percorre o caminho de Galta, na Índia, como se percorresse os caminhos obtusos da linguagem em direção à presença. Nesta obra, a busca da presença se converte numa busca da amada: Esplendor figura entre as imagens do mar e do vaivém erótico das ondas, atraentes, espumantes e quentes. Mas, no caso de Noturno, trata-se apenas da memória histórica embrenhada na memória pessoal do poeta. Não por menos, assombram-no certos arrependimentos, como certos posicionamentos de juventude revistos em fins de vida:

O bem, quisemos o bem:

botar o mundo em ordem.

Não nos faltou inteireza:

faltou-nos humildade. (PAZ, 2015, p. 176)

O mea culpa presente nestes versos tem um desdobramento que leva, por fim, à isenção de qualquer pecado, a uma espécie de apocatástase ritual de sua própria biografia:

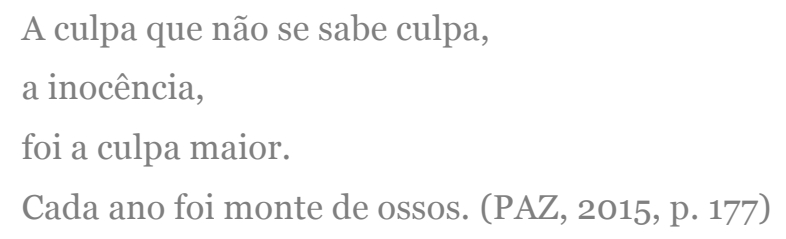

A menção ao amontoado de ossos é uma crítica à violência promovida pelo Estado em nome não apenas das ideologias, mas dos projetos de poder que, em nome do positivismo porfirista, do socialismo, do cristianismo, obnubilaram a liberdade humana, segundo a visão do autor que fora, outrora, partidário e interlocutor ativo, apesar de opositor, da esquerda mexicana. Ao rever, portanto, os 
seus erros, o poeta defronta-se com a quebra da unidade de um ideal de futuro que consagrava todo o presente de sua juventude. O despovoamento desse futuro - tornado acinzentado - entretanto, não deve se converter num niilismo que estes versos parecem suscitar. Paz, ainda que reconheça que os momentos irônicos possam ser aqueles que mostram não apenas o vazio da linguagem, mas o próprio vazio de sentido da existência, sempre diz que o poeta deve dizer, deve procurar através de seu trabalho, recriar a linguagem para, com isto, recriar o sentido e refazer o tempo.

Ademais, é nesta mesma página que os versos de Paz encontram a trouvaille que, a nosso ver, oferece, se não uma harmonização do par paradoxal, uma conciliação entre as figuras da ironia e da analogia, mostrando que de uma podemos saltar à outra:

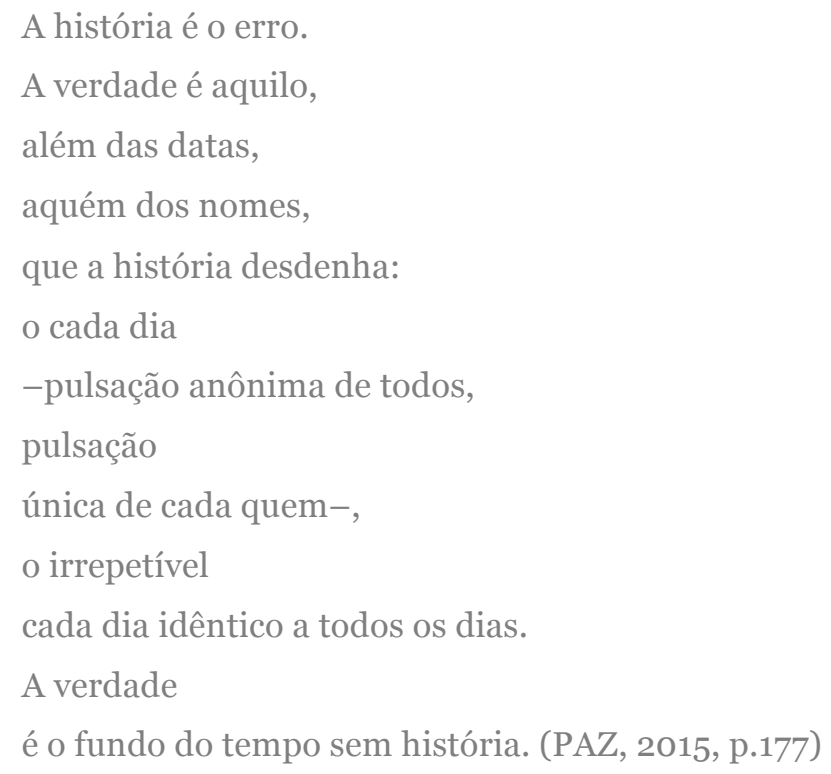

O que seria, pois, este fundo do tempo sem história? Que espécie de verdade está posta para além das datas? Há uma citação de Annie Le Brun que, a nosso ver, responde a esta questão ao evidenciar que espécie de fatos os surrealistas procuravam trazer à luz. Para a autora "escrever não teria outra serventia senão a de evidenciar a coerência de tantos acontecimentos habitualmente negligenciados por terem sido considerados negligenciáveis" (LE BRUN, 2012, p.151). Escrever é revelar a outra margem, o maravilhoso, o irrecuperável instante em que uma experiência se fez. E é pela escrita, pela palavra poética, que os contrários se 
enlaçam e estabelecem um par dialético que, ainda que não se resolva, constroe uma imagem. Assim como o tempo, a imagem é "marca da condição humana", pois esta, se não revela o ser, o recria (PAZ, 2012, p. 104). Cada recriação do ser se dá no interior de um instante cuja potência é fazer vicejar a presença, aludida por nós no início deste texto. A imagem nos revela uma possibilidade de conciliação com o mundo, de ruptura da fronteira espessa da subjetividade. Por isso, Paz diz: "há um ponto em que isto e aquilo, pedras e penas, se fundem. Esse momento não está antes nem depois, no princípio ou no fim dos tempos. [...] É cada momento. É o próprio tempo se gerando, emanando. [...] Jorro, fonte” (Idem p. 109). Ou seja, é a origem. A palavra imagética da poesia é uma palavra de fundação: da existência, do ser humano e de sua condição originária, o tempo. Em suma, diante do erro da história, a imaginação e a poesia podem figurar como ensaios de novas formas de ser.

Em outras palavras, o momento onde o par inconciliável "unidade do absoluto" e "justaposição sincrônica” se tocam, apesar de conservadas suas identidades, é no interior do instante. Este instante é o instante poético, no qual a vivência do tempo se torna experiência, graças à sua intensidade e vivacidade, bem como à sua natureza estritamente qualitativa em detrimento de sua natureza quantitativa. Esta é a verdade que Octavio Paz deseja afirmar no interior de sua poesia e é no interior deste instante que ele verá crescer a força da presença. Se a rotina do relógio nos conduz à caducidade e a história nele nos aprisiona, como bem aponta o poeta Borges em El Instante:

\section{$[\ldots]$}

El presente está solo. La memoria

erige el tiempo. Sucesión y enganõ

es la rutina del reloj. El año

no es menos vano que la vana historia.

[...]

El hoy fugaz es tenue y es eterno; otro Cielo no esperes, ni otro Infierno. (BORGES, p.310)

Este instante, o poeta deve evocá-lo como ponto de ruptura do continuum que se instaura na vida cotidiana, prática e útil. O instante poético é um evento de restabelecimento com o sentido e com a experiência, ainda que a linguagem 
traia o poeta. Porém, tal como num movimento amoroso, em que Eros realmente se revela filho de Poros e Pênia, como nos narra Platão em O Banquete, o poeta tal qual o amante - deve ser capaz de consagrar aquela partícula temporal em que a intensidade da experiência é capaz, por si só, de justificar uma vida.

\section{REFERÊNCIAS}

LE BRUN, Annie. História de um desastre. In: BRETON, André. Nadja. São Paulo: Cosac Naify, 2012.

BORGES, Jorge Luis. Nova antologia pessoal. São Paulo: Companhia das Letras, 2013.

PAZ, Octavio. La llama doble. Barcelona: Seix Barral, 1993. . La casa de la presencia: poesía e historia. Obras Completas, vol. I. Ciudad de Mexico: Fondo de cultura económica, 2003.

. Los hijos del limo. In: La casa de la presencia: poesía e historia. Ciudad de Mexico: Fondo de Cultura Económica, 2003.

. 0 Arco e a Lira. Trad. Ari Roitman e Paulina Wacht. São Paulo: Cosac Naify, 2012.

. O Labirinto da Solidão. Trad. Ari Roitman e Paulina Wacht. São Paulo: Cosac Naify, 2014.

. Noturno de San Ildefonso. Trad. Horácio Costa. Revista 0 que nos faz pensar?, PUC, Rio de Janeiro, 2015.

. A busca do presente. Trad e org. Eduardo Jardim. Rio de Janeiro: Bazar do Tempo, 2017. 